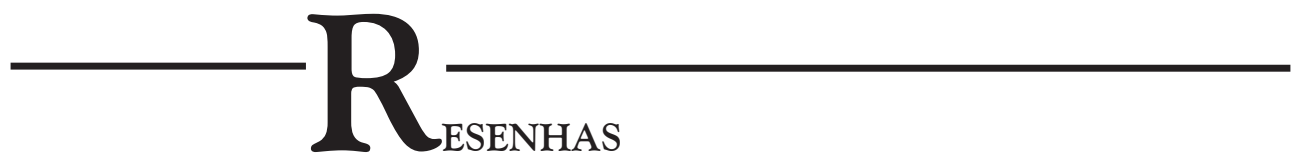

FERRETTI, Sérgio. Repensando o sincretismo. 2. ed. São Paulo: Edusp; Arché Editora, 2013, 280pp. Orelha de Mundicarmo Ferretti, prefácio de Reginaldo Prandi, contracapa de João Luiz Carneiro.

Hermes de Souza Veras

\title{
REPENSANDO REPENSANDO o SinCRETISMO
}

Sérgio Ferretti é nome comum na literatura sobre religiões afro-brasileiras. Realizou seu mestrado na UFRN e o doutoramento na USP, ambos em Antropologia Social, com importante orientação de Kabengele Munanga nas duas etapas. Atualmente, Ferretti é professor emérito da Universidade Federal do Maranhão.

A última edição de seu Repensando o sincretismo (RS), parceria entre a Arché Editora e a EDUSP, supre a necessidade de circulação e consulta da obra, pois a primeira edição é de 1995 e o debate e as controvérsias sobre o sincretismo ganharam novas percepções e críticas. Apesar de a segunda edição não incorporar esse debate mais recente, a leitura a partir do debate contemporâneo a respeito do tema pode gerar reflexões futuras. No caso do livro em questão, se reaviva o interesse pelo tambor de mina, religião de matriz africana predominante na região Norte do Brasil. Conforme afirma Reginaldo Prandi na introdução, RS funciona como continuação de Querebentã de Zomadônu (2009), livro originado da dissertação de mestrado de Ferretti. Embora seja possível lê-lo independentemente, é importante ressaltar a complementariedade entre as duas obras.

RS é uma pesquisa de porte que apresenta etnografia construída entre 1973 e 1990, dialogando com as principais teorias antropológicas vigentes em sua época (fins 
da década de 1980 e inícios da de 1990). Embora possua um tema central, o sincretismo nas religiões afro-brasileiras, muitos outros temas vazam pelas linhas escritas, como a relação entre tradição e modernidade, além das resistências da "cultura popular" e de matriz africana em relação à sociedade envolvente.

Para dar conta dessa complexidade, o livro é dividido em duas partes. A primeira, basicamente teórica e de levantamento bibliográfico, traz um balanço geral sobre a literatura de tema afro-brasileiro na região Norte, além de perpassar pela ótica das diversas escolas de pensamento que tentaram compreender a questão. Ferretti também dialoga sobre o tema da identidade étnica, associando-a ao sincretismo. A segunda parte se constitui em relatos etnográficos, tratando de diversos rituais da mina em que estão presentes, em diferentes níveis, o catolicismo eclesiástico e popular. Nesses relatos, as pessoas entram em contato com voduns, orixás, santos, princesas, reis e gentis, personagens atuantes no tambor de mina.

A maior parte do material empírico é da Casa das Minas, que "foi organizada na primeira metade do século XIX por negros minas procedentes do Daomé, sob a proteção de Zomadonu, vodum que lidera o culto aos ancestrais da família real” (p. 127).

Por essa razão, Ferreti aponta que a Casa das Minas é uma religião formada por uma realeza africana em meio à população subalternizada de São Luís. Assim, para adentrar na Casa das Minas é necessário algum parentesco com a casa, mesmo que religioso, embora existam algumas exceções, quando amigos do terreiro são convidados para participarem.

Logo no início da obra, dissertando sobre a metodologia da pesquisa, Ferretti traz o necessário debate sobre as relações entre oralidade e escrita nas religiões afro-brasileiras, relatando o quão presentes são os livros sobre religião, nos próprios terreiros, sendo tanto consumidos como publicados por pais e mães de santo. Nesse ínterim, o autor reflete que a produção escrita sobre as religiões afro está ligada às disputas de poder e espaços, pois alguns pesquisadores questionam a legitimidade de livros escritos por religiosos, alegando que eles não dominam muito bem o código da escrita, assim como há críticas do movimento negro em relação aos antropólogos que constroem suas carreiras escrevendo sobre terreiros. Aqui, seria interessante atualizar o debate sobre a apreensão cosmológica de livros entre as comunidades afro-brasileiras, pois, como se sabe, a simples interpretação de que os livros são usados como fonte de prestígio e poder prejudica e exotiza as pessoas protagonistas nesse processo. O livro de Ferretti nos possibilita ir além dessa simplificação repetitiva.

Nesse sentido, o autor acredita que estão relacionadas as questões levantadas sobre a ética na pesquisa antropológica - aqui, ele está dialogando diretamente com o movimento pós-moderno na Antropologia - e o sincretismo, por se tratarem ambos das relações entre diferenças dinâmicas: tradição/modernidade, pesquisador/nativo, catolicismo/religiões afro-brasileiras, sincretismo/antissincretismo, embraquecimento/africanização e daí por diante. A respeito do antissincretismo, o autor se refere às manifestações de lideranças do candomblé que defendem uma reafricanização de sua 
religião, distanciando-se de elementos católicos, espíritas e ameríndios. Para Ferretti, esse manifesto é reflexo de articulações políticas entre lideranças religiosas e o movimento negro, além de se relacionar com aspectos das identidades negras no Brasil.

Em seu estudo, portanto, o sincretismo esteve ligado inicialmente a uma "dependência aparente da mina ao catolicismo" (p. 247), que:

Decorre de mais de um século e meio de circunstâncias históricas em que sua religião foi proibida, perseguida e conseguiu sobreviver com grandes dificuldades. Estão convencidos de que a religião da mina tem mais forças, mesmo estando inferiorizada. Talvez a força simbólica dos mais fracos (p. 247).

Essa força, que hoje poderíamos chamar de cosmopolítica, é elemento crucial na obra de Ferretti, que disserta, diversas vezes, sobre criatividade e resistência entre populações subalternizadas. Essa é uma das razões que fez o antropólogo focar sua análise e etnografia nos rituais, pois, na Casa das Minas, a mitologia se apresenta de forma silenciosa e misteriosa, portanto, "o relato mitológico é reduzido" (p. 135). Já o ritual, segundo Sérgio Ferretti, acontece de maneira minuciosa, detalhada e abastada de criatividades e expressividade. Por essa razão, Ferreti se detém nos rituais realizados na Casa das Minas, pois é a partir deles e de seus contextos que se atualizam aspectos da história dos voduns e de suas relações com suas filhas.

Diante disto, Ferretti identifica quatro momentos do sincretismo no Tambor de Mina, são eles: a) separação, b) mistura, c) paralelismo ou justaposição, d) convergência ou adaptação. Esses quatro tipos são apresentados na primeira parte da tese, junto às diversas etapas do pensamento antropológico e suas percepções sobre o sincretismo: evolucionismo, culturalismo, escola sociológica francesa (reinterpretada por meio da obra de Roger Bastide), até chegar em seus contemporâneos, que debatiam sobre a "pureza nagô" e seus desdobramentos.

Ao escolher priorizar os rituais (o feito, a performance), o antropólogo se situa num longo debate da história do pensamento antropológico. Sem polarizar mito/rito, sua preferência pelo ritual sugere, além de um entrave metodológico por conta do silêncio e o segredo encontrado em campo, uma atenção à criatividade envolvida nos rituais, a condensar conhecimentos, experiências, estéticas e resistências da "cultura popular".

A partir da sua análise dos rituais, Ferreti traz alguns exemplos. Na festa de Averequete, que acontece na Casa das Minas, há uma aproximação entre o Tambor de Mina e o catolicismo, embora eles funcionem como compartimentos que, apesar de se comunicarem, não se confundem. Já no Arrambam (fechamento dos terreiros no início da Quaresma), o sincretismo ocorre apenas na confluência temporal - Arrambam e Quaresma ocorrem simultaneamente, entretanto, apresentam propósitos distintos. No ritual fúnebre do tambor de choro, há convergências de concepções sobre a morte entre o tambor de mina e o espiritismo kardecista; misturas de rituais 
católicos com o de tambor de mina (tambor de choro e missa do sétimo dia); e, finalmente, um paralelismo entre o tambor de mina e a maçonaria.

Ao apresentar o sincretismo dentro da Casa das Minas, Ferretti sinaliza para a presença de convergências, misturas, contatos, paralelismos e oposições entre o tambor de mina e as religiosidades envolventes. Desta forma, o autor descreve e demonstra o movimento de atualização da tradição, desmontando o mito de que para ser tradicional um terreiro tenha que se fechar em si mesmo - e para qualquer um que tenha prestado atenção nos terreiros, concordará que a percepção do terreiro enquanto uma "ilha" isolada não faz o menor sentido, impedindo justamente que se perceba o quanto essas pessoas e suas entidades estão em movimento, resistindo e produzindo vida.

$R S$ é uma obra fundamental para se lançar a uma nova perspectiva sobre o sincretismo, pois apresenta uma revisão bibliográfica ainda consistente, além de etnografia de rituais praticados no tambor de mina. A parceria entre os estudos sobre o tema e a pesquisa empírica incentiva que as pesquisas contemporâneas continuem conjugando esses dois aspectos da pesquisa antropológica com populações afro-brasileiras.

A leitura ou releitura de RS deve ser incentivada entre os estudiosos da religião, mesmo se seus temas de estudo não forem os diretamente tratados pelo livro. Contudo, gostaria de acrescentar alguns comentários finais que transcendem o livro em questão. Sabemos que o sincretismo foi debatido e combatido. Algumas reflexões posteriores ao livro merecem aqui destaque, tais como na percepção do sincretismo enquanto composição, o debate sobre os (contra) sincretismos e (contra)mestiçagens ${ }^{1}$, e, especialmente, a reflexão de Antônio (Nego) Bispo (2015) sobre colonização e contracolonização. É interessante pensar a contracolonização como o próprio movimento que possibilitou que africanos, seus descendentes, populações de terreiro, quilombolas e indígenas resistissem e vivessem. Assim, saindo da seara do livro de Ferretti, o que foi chamado de sincretismo afro-católico pode ser lido como uma postura contracolonial, desde as manifestações de transe entre os africanos batizados e catequizados no Congo dos séculos XVII e XVIII, apontados por Gisèle Cossard (1976), até as formas contemporâneas que podem ser acompanhadas entre diversos coletivos e comunidades. Fica o incentivo para que prestemos atenção no que as pessoas protagonistas desses processos nos têm a dizer sobre tudo isso. Nesse quesito, não cabe apenas a pesquisadoras e pesquisadores a afirmação ou negação da importância do conceito de sincretismo.

\section{Referências bibliográficas}

ANJOS, José Carlos Gomes dos; ORO, Ari Pedro. (2009), A festa de Nossa Senhora dos Navegantes em Porto Alegre: sincretismo entre Maria e Iemanjá. Porto Alegre: SMC.

COSSARD-BINON, Gisèle. (1976), "Origines Lointaines du Syncretisme Afro-Catholique au Brésil et Perspectives d'Avenir”. Afro-Ásia, no12: 161-166. 
PAZZARELLI, Francisco; SAUMA, Julia F; HIROSE, Maria Belén. (2017), "(Contra)Mestiçagens Ameríndias e Afro-Americanas".R@U 9(2):9-10.

SANTOS, Antônio (Nego) Bispo dos. (2015), Colonização, quilombos. Modos e significados. Brasília: INCTI.

\section{Notas}

1 Uma atualização do debate pode ser conferida no dossiê (contra)Mestiçagens Ameríndias e Afroamericanas, publicado pela R@U, revista de antropologia da UFSCar, cf. Pazzarelli, Sauma, Hirose (2017). Sobre o sincretismo enquanto criação, vale consultar Anjos e Oro (2009).

Submetido em: 28/11/2016 Aceito em: 20/08/2018

Hermes de Souza Veras (hermesociais@gmail.com)

Doutorando no Programa de Pós-Graduação em Antropologia Social da Universidade Federal do Rio Grande do Sul - Porto Alegre - RS - Brasil. 